\title{
HISTOLOGICAL ANOMALIES IN GONADS OF OREOCHROMIS NILOTICUS (CICHLIDAE) FEEDING ON ETHYNYLTESTOSTERONE AND ACTIVE YEAST.
}

\author{
Samia .G. MOHARRAM and EL-Said. H. Ebiary \\ National institute of Oceanography \& Fisheries - Alexandria.
}

Key words: histological anomalies, gonads, ethynyltestosterone. active yeast.

\begin{abstract}
M ale-population of Tilapia nilotica was produced with $17 \alpha$ ethynyltestosterone at $60 \mu \mathrm{g} / \mathrm{g}$ diet. Subsequently fry were fed $1.2 .3,4$ and $5 \mathrm{~g} / \mathrm{kg}$ active yeast diet for 70 days. Fish fed on dietary yeast were significantly heavier than the control. The percentage of males was 62.1. Ovotestis condition was found. Histological anomalies of the gonads of both sexes have been observed. Sterilization of the testis was complete at all levels of yeast diet. Dietary treatment had a destructive effect on the histological appearance of gonadal development.
\end{abstract}

\section{INTRODUCTION}

It has been well established that sex steroids are effective in modifying and directing the gonadal sex differentiation in teleosts fishes when administered in adequate doses and during appropriate stages of gonadal development (Yamamoto, 1969).

Tilapias are fecund and are able to reproduce at a relatively small size (Lowe; 1955). Practices and suggestion included monosex culture (Hickling, 1968; Semakula and Makoro, 1968; Shell, 1968 and Guerrero, 1975) and sex reversal (Celmens and Inslee, 1968: Chew and Stanely, 1973). Yamamoto (1986) obtained 100\% sex reversal of genetic females in the medaka Oryzias latipes, with ethynyltestosterone. In the culture of certain species of Tilapia. prolific breeding results in small size at harvest, which can be avoided by monosex culture. Guerroro (1975) used ethynyltestosterone treatment in blue tilapia Tilapia aurea to produce stocks containing a high percentage of males. Nakamura (1975) disclosed that, in Tilapia mossambica, oral administration of androgen exerts a different 
different influence on gonadal sex differentiation according to the dosage and duration of androgen treatment.

In the recent years, a great concem is given to fish diets in order to be economic and performed. Accordingly, attempts have been made to find out additive food which could be formulated at economic costs for fish production. For this goal, it can be shown that active yeast is used as microbial additive for protein source to improve growth performance of Oreochromis niloticus (Abd-Elhalim et al., 1989; Kobeisy and Hussein, 1995).

Also, yeast has been used as complementary protein source in fish diets together with fish meal. However, crude protein of yeast comprises a high content of non-protein nitrogen (De Groot, 1977)

The present study was undertaken to find out the effect of oral administration of androgen or adding of active yeast Saccharmyces serviaein to diets on gonad development of Oreochromis niloticus.

\section{MATERIAL AND METHODS}

Male Oreochromis niloticus was produced by androgen treatment. The synthetic androgen used was $\alpha 17$-ethynyltestosterone (ET60; Sigma). The fry of experimental groups were given the hormone-containing diet $(44.6 \%$ crude protein) once a day for 28 days after birth. The fry of $8-10 \mathrm{~mm}$ total length and $1.66 \pm 0.1 \mathrm{~g}$ total weight and approximately $4-5$ weeks old were divided into six groups -20 fry in each group ; Each group (duplicated) was stocked in a 120$\mathrm{L}$ aquarium with aerated and dechlorinated tap water. Water temperature was thermostatically controlled at $28 \pm 1$. Based on the criterion of Eckstein and Spira (1965) the fry were sexually undifferentiated.

Six diets were formulated to contain $35 \%$ crude protein. A control diet (No.1) which contained $27.1 \%$ fish meal, $28.4 \%$ soybean meal, $25 \%$ yellow corn, $3 \%$ yellow corn oil and $2 \%$ vitamin and minerals premix. While the other tested diets from NO.2 to No.6 contained 1,2,3,4 and $5 \mathrm{~g}$ active yeast per one $\mathrm{kg}$ control diet respectively. Five groups were fed yeast diet and one served as a control. Chemical analyses of the control diet and the five supplemental diets are shown in Table (1).

Fish were subsequently fed on their pelted at $5 \%$ of body weight twice daily, 6 days adjusted every week for 70 days. During experiment the water of each aquarium was changed every three days. 
At the end of the experiment, the fish were collected, weighed and measured. Fishes were dissected, gonads and liver of experimental and control fish were extirpated and the gonado-somatic (GSI) and hepatosomtic (HSI) indices were calculated as follows:

$$
\begin{aligned}
& \text { GSI = gonad weight } \times 100 / \text { gutted weight. } \\
& \text { HSI = liver weight } \times 100 / \text { gutted weight. }
\end{aligned}
$$

Gonads were fixed in Bouin's, dehydrated, sectioned and stained with Hematoxylin and Eosin.

\section{RESULTS}

\section{Survival and growth}

No gross abnormalities were observed in treated fish. The survival of experimental fish after 70 days was not significantly different $(P>0.05)$ from that of controls. The overall mean survival rate for the experimental fish was $78.3 \%$.

The mean weights of experimental fish at the end of the experiment were generally higher than that of the control (Table 2). Significant difference $(\mathrm{P}<0.05)$ between the mean weights of fish fed on yeast treated and controls indicating that treated fish had better growth than controls.

Total length did not differ $(P>0.05)$ between the control and yeast- treated fish during the period of experiment.

\section{Effectiveness of Androgen for Inducing Sex Reversal}

The combined group consisted of $62.1 \%$ males, $20.7 \%$ females and $17.2 \%$ ovotestis.

\section{Gonads}

The ovaries of control females were in no case furnished with any trait of testicular structure in any region of ovaries. The testis of $O$. Niloticus belongs to the radial type.

\section{Control}

The different germ cells of spermatogenesis were identifiable. The central part of the testis was loaded with spermarozoa. The spermatogonia were small, mostly peripheral and spermatocytes and spermatids were found in fair amounts (Fig. 1). The mean GSI was 0.7 . 
The control females (100days old) had ovaries with oocytes developing to ripe stage (Fig.2). Most oocytes were normal in aspects. The ripe ova contained abundant yolk materials being surrounded with a sheath of follicular cells. The interfollicular space appeared clear. Atretic oocytes were rare. The mean GSI was 1.2.

\section{Histological anomalies}

The testis

The spermatogenesis in the testes of fish fed on yeast for 70 days were notably affected. Definite testicular injury was revealed by marked discoloration and abnormal size and divided into two unequal portions. The upper portion was small and tapering, while the lower portion was blunt. Germ cells including spermatogonia were clearly reduced in number and mostly disappeared from the gonads.

Histological examination of testis sections $(1 \mathrm{~g} / \mathrm{kg}$ diet yeast) showed marked changes, the most prominent of which were marked proliferation of the connective tissues, extensive haemorrhage necrosis and pyknosis. Inside the seminiferous lobule, complete necrotic and degenerated sperm follicles were seen (Fig. 3). Many blood vessels were packed with erythrocytes were visible between the testes lobules. The wall of blood vessel had collapsed in places and many erythrocytes had aggregated to invade the lobules causing the lobules boundary cells to disintegrate and the nuclei to become pyknotic. Germ cells were absent (GSI=1 Fig. 3).

In fish fed on $2 \mathrm{~g} / \mathrm{kg}$ diet yeast (GSI $=2$ ) the interiobular connective tissue was packed with erythrocytes which surrounded the lobules causing some sort of hypertrophy and inter- lobular edema was observed. The lobules had disrupted sheaths and appeared empty having some pyknotic nuclei and spermatocytes were ruptured (Fig. 4).

Examination of fishes fed on $3 \mathrm{~g} / \mathrm{kg}$ diet yeast showed remarkable malformation and disruption of their testicular lobules. The lobules lost their membranes. Malformation of spermatogonia which became enlarged in size and their cytoplasm degenerated. Also, dense chromatin materials were seen. Dislocation of nuclei of spermatogonia was observed. The spermatozoa in the seminiferous lobules lost their normal appearance with short tails. Necrotic appearance was noticed as indicated by the presence of numerous pyknotic nuclei (GSI=1.2 Fig. 5).

Microscopic examination of the testes of fish fed on $4 \mathrm{~g} / \mathrm{kg}$ diet yeast (GSI $=1.5$ ) displayed an abnormal increase of pyknosis, which lead to necrosis, arrest of spermatogenesis. The lobular wall 
degenerated completely. The germ cell cysts of early spermatogenetic stages including the spermatogonia were, however, evidently absent and those of more advanced stages comprising transforming spermatids and spermatozoa were abnormal in feature. Pyknosis of primary and secondary spermatocytes was observed (Fig.6).

Testes of fish fed on $5 \mathrm{~g} / \mathrm{kg}$ diet yeast showed sever damage where the spermatogonia became enlarged in size with dark chromatin dense. The sperms exhibited varying degrees of malformation, remarkable degeneration of sperm tails and collapse of sperm's heads which have dark pyknotic nuclei. Disappearance of all intermediate stages between spermatogonia and sperms. Misshapen and damaged lobular walls and blood vessels were noticed $(\mathrm{GSI}=2.2$, Fig. 7).

\section{The ovary}

The ovaries of experimental groups had no trait of testicular structure in any region. On the other hand, females of the same age fed on yeast diets examination of ovaries sections revealed normal structure, but marked increase of atretic oocytes, hypertrophy of granulosa layer abnormal yolk formation as evidenced by non-fusion of yolk droplets and rapture of epithelial follicles. The nuclear envelope disappeared and the chromatin disintegrated. The very thin zona radiate ( $Z R$ ) was thrown into folds and penetrated the degenerated cytoplasm (Fig. 8). Simultaneously, the number and size of granulosa cells increased and they began to invade the shrunken nucleoplasmic mass. The steady progress of atresia resulted in the loss of cytoplasm, and the degenerating oocytes were occupied by phagocytic derived from the follicular cells and granulose layer. The yolk mass exhibited various degrees of liquefaction and a number of different sized vacuoles appeared (Fig. 9). Zona radiata had disappeared and the nucleus was no longer discernible as a separate structure.

The small oocytes in the previtellogenic stage showed nuclear malformations, where their chromatin bodies became separated from the nucleoplasm, also edema and the interfollicular tissue contained leukocytes, and red blood cells (Fig. 10). In general, all the examined ovaries revealed signs of severe damage and different stages of atresia.

The histological observations showed that younger germ cells such as oogonia and synaptic oocytes were undetected through the entire gonadal region. The ripe oocytes were very few in number. 
Examination of sections of spent female fed on yeast revealed a complete degeneration of all oocytes, loss of cytoplasm and rupture of oocyte walls (Fig. 11).

The GSI values of ripe females fed on 2,3 and $4 \mathrm{~g} / \mathrm{kg}$ yeast were very high $(4.5,9.7 \& 8.4$ respectively), while the GSI value of control ones were 1.2 (Table 2).

An interesting feature detected in the testes was the occurrence of oviform germ cells intermingled among male germ cells. These cells were rounded in contour and appeared mostly in the central region of the testes singly or in a few numbers. It closely resembled the oocytes in the period of the first growth phase. Sometimes the nucleus of the oviform cell was provided with several nucleoli arrayed in close contact with nuclear membrane (Fig. 12).

Examinations of gonad sections revealed that ovotestes condition was observed among specimens examined and its percentage was $17.2 \%$. The histological observations showed that, their gonads were in complete degeneration, quite similar to those of males (Fig. 13).

The hepatosomatic index (HSI) of the groups fed active yeast were significantly different $(\mathrm{P}<0.05)$ from that of the control group. It was found that fish fed on 2 and $3 \mathrm{~g} / \mathrm{kg}$ diet yeast had the highest values of HSI (Table 2).

\section{DISCUSSION}

The fish gonad, a possible indicator of physiological disturbances, has rarely been studied with relation to the possible histopathologic effects of food.

In the present study histopathological changes were observed in the gonads of O.niloticus fed with different levels of active yeast (Saccharomyces servisiaein) in diet.

In the present experiment on O.niloticus, the mortality rate was low. This result agrees closely with that of Yashouv and Eckstein (1965) who indicated that tilapia treated with male hormone during the first month of life had low mortality rate.

In this study, the percentage of males treated with ET-60 was $62.1 \%$. This result differs apparently from that obtained by Guerrero (1975) in which $100 \%$ males of Oreochromis aureus was produced with the same androgen. 
In the present study, according to Eckstein and Spira (1965) the fry of O.niloticus at 4-5 weeks old were sexually undifferentiated at the beginning of feeding with yeast diets.

Androgens, especially when given to fry or juvenile fishes at high dosage levels and for long duration of days, occasionally lead to complete sterility of the gonad (Takahashi, 1977). In the rainbow trout salmo gairdneii Jalabert et al (1975) stated that the oral administration of androgen diet for 5 months to juvenile fish could produce some sterile adults.

Takahashi (1977) indicated that all affected testes guppy Poecilia reticulate, 35 days after birth were improved and liberated after hormone withdrawal from a sever development suppression to assume eventually a nearly normal structure of the testes. Sterilization of guppy $P$. reticulata was complete only when the androgen treatment was protracted over 70 days following birth. Donaldson and George (1982) concluded that low dose of androgen caused male differentiation, while a high dose of androgen effectively sterilized both male and female. Guerrero (1975) reported that gonads of

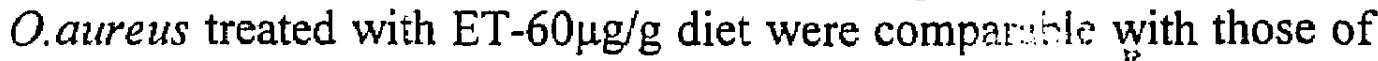
the control, androgen had no gross morpholog!cal and; histological effect on the gonads. Also, he stated that treated males spawned with females.

In the present experiment on O.niloticus small dose of androgen was given to fry for a short period (28days after birth). Also, degeneration of the gonads of both males and females were not observed in the group of fish fed on control diet for 70 days. So, from the above results, it can be concluded that ET-60 $\mathrm{g} / \mathrm{g}$ diet had no effect on the gonad development.

Guerrero (1975) found that no ovotestis condition was observed among the specimens examined of Oaureus treated with ethynyltestosterone. On the contrary, the results with the same androgen in the present study indicted that ovotestis condition was noticed among $17.2 \%$ of the gonads examined of $O$.niloticus.

Yamamoto, (1958) observed the appearance of oviform cells in the testes of the medaka, Oryzias latipes, subjected to the androgen treatment, but he regarded them as degenerated enlarged gonia, but not as true oocytes because there were no follicle cells, and the cells showed a strong affinity for dye. Also, Takahashi (1977) found this oviform cell in the testes of guppy. The oviform cells existing in the affected testes of $O$ niloticus truely resemble the young oocyte in the 
first growth phase. They were too scanty and too spars in distribution to be regarded as spermatogonia forced to undergo degeneration by the treatment. A disturbance of testicular stromal tissue influenced by the androgen treatment in the present study might have some significance in the occurrence of oviform cell in the affected testes of O.niloticus (Takahashi, 1975).

In the present study, although the administration of ET-60 was commenced prior to the stage of ovarian differentiation, it could not completely prevent the appearance of oocytes in affected gonads of genetic females during gonadal development. As described in Tilapia mossambica, treated with androgen, some germ cells in the gonad of possible genetic females under went oogenesis even under the influence of androgen (Nakamura, 1975).

Yeast had a high nutritive value not only because of its protein content (15\%), but also because of simultaneous presence of protein, vitamins and enzymes (DeSilva et al. 1989). The present study revealed that fry of $O$.niloticus fed on dietary yeast were significantly $(\mathrm{P}<0.05)$ higher in body weight than those fed on control diet. This finding agrees closely with those of Abd-El-halim et al. (1989) and Hussein (1998) on the same species. In this study, body length did not differ $(\mathrm{P}>0.05)$ between the control and yeast -treated fish during the experiment, indicating that yeast did not affect early growth.

Tacon and Cook (1980) stated that yeast has high content of nucleic acids (6-11\% DNA \&RNA) which accumulated in the blood. Feeding experiments have shown that yeast have high lysine which has a role with fish reproduction (Edwards and Hassall, 1980). In the present experiment on O.niloticus histopathological changes and complete sterilization and malformation of both testes and ovary were realized only when the fry ( 30 days old) were fed on the different levels of yeast. This might be explained by the high protein content in dietary yeast given during the maturation cycle of the gonad in O.niloticus as indicated by Washburn et al. (1990). Also, yeast is a source of vitamin B6 which is essential cofactor for the transaminases enzymes which is also known as amino transferases (Edwards and Hassall, 1980). Moreover, the metabolism of both methionine and cysteine, which are important in protein anabolism, dependent on the availability of vitamin B6 (Tryfiates, 1986). For this reason, the extreme physiological disturbance or even death in animals is thought to arise by an increasing or a deficiency of vitamin B6 (Edwards and Hassall, 1980). 
Contrasting to the dietary protein requirement ( $28 \%$ ) for young tilapia, weighing 1.5g (De-Silva et al. (1989), the dietary protein for young tilapia weighing $1.6 \mathrm{~g}$ at the beginning of the experiment was $44 \%$, then it decreased to $35 \%$ in the present study. It is widely accepted that too much energy in relation to protein can prevent fish from consuming enough protein.

Since histological anomalies were observed in the tilapia gonads the question remains as to the mechanism and pathway by which yeast and androgen or yeast only disrupt the normal gonadal cycle. The present experiment gives conclusive data that yeast directly affects the gonad development and lead to complete sterilization of both sexes. However, the specific function of yeast in endocrine tissues is still not fully understood and need further investigations.

\section{REFERANCES}

Abd EL-Halim, A. A. ; Nour, A. ; Omar, E. and Abd EL-latif, M. G. (1989). Utilization of yeast (Sacchromyces cervisise) in fish feeds.2). Effect of different levels of active yeast or inactive yeast on growth performance and feed utilization of Nile tilapia Oreochromis niloticus L., 2nd Alex. Conf.Fd. Sci. Tech., pp.369-405.

Chew, L. and Stanley, J. G. (1973). The effects of methyltestosterne on sex reversal in bluegill. Prog. Fish Cult., 35(1): 18-21.

Clemens, H. P. and Inslee, T. (1968). The production of unisexual broods by Tilapia mossambica sex-reversed with methyltestosterone. Trans. Amer. Fish. Soc. 97(1):18-21.

DeGroot, A. P. (1977). Proceeding of the Regional Seminar on Microbial Conversion Systems for Fodder Production and Waste Management. KISR, Nov. 12-17, Kuwait,133-143.

DeSilva, S. S. ; Gunasekora R. M. and Ataoattu, A. (1989). The dietary protein requirement of young tilapia and evaluation of the least cost dietary protein levels. Aquacult., 20:117121. 
Donaldson, E. M. and George, A. H. (1982). Sex control in fish with particular reference to Salmonids. Can. J. Aquat. Sci., 39:99-110.

Edwards, N. A. and Hassall, K. A.(1980). Nitrogen metabolism and the biochemistry of amino acids. In: Biochemistry and Physilogy of the cell, $2^{\text {nd }}$ edition, pp.303-335, Mc GrawHall Book Compny (UK) limited

Eckstein, B. and Spira, M. (1965). Effect of sex hormones on gonadal differentiation in chiclid, Tilapia aurea. Biol. Bull. 129: 482-489.

Guerrero, R. D. (1975). Use of androgens for production of all-male Tilapia aurea. Trans. Amer. Fish. Soc., 2: 342-348.

Hickling, C. F. (1968). The farming of fish. Pergamon, N.Y.88 pp.

Hussein, S. Y. (1998). Impact of poultry droppings supplemented with Ascorbic acid and live yeast on Nile tilapia Oreochromis niloticus L performance. Assiut Vet. Med J. 212-235.

Jalabert, B. ; Billard, R. and Chevassus, B.(1975). Perliminary experiments on sex control in trout: Production of sterile fishes and simultaneous self-fertilizable hermaphrodites. Ann. Bioch. Biogys. 15:19-28.

Kobeisy, M. A. and Hussein, S. Y.(1995). Influence of dietary live yeast on growth performance and some blood constituents in Oreochromis niloticus. 'Proc. $5^{\text {th }}$ Sci. Conf. Animal Nutrition, 1: 417-425. Ismailia, Egypt.

Lowe, R. H. (1955). The fecundity of Tilapia species. E. Afric. Agric. J., $21(1): 45-52$.

Nakamura, M. (1975). Dosage-dependent changes in the effect of oral administration of methyltestosterone on gonadal sex differentiation in Tilapia mossambica. Bull. Fac. Fish. Hokkaido Univ., 26: 99-108. 
Semakula, S. N. and Makoro, J. T.(1986). The culture of Tilapia species in Uganda. Proc. FAO World Symposium on warm -water pond fish culture, May 18-25, Rom, Italy. FAO Fish Rep., 44 (2): 161-164.

Shell, E. W. (1968). Mono-sex culture of male Tilapia nilotica in pond stocked at three rates. Proc. FAO World Symposium on warm -water pond fish culture, May 18-25, Rom, Italy. FAO Fish Rep., 44(4): 353-365.

Tacon, A. G. W and Cook, D. J.(1980). Nutritional value of dietary nucleic acids to trout. Nutr.Rep.Int., 22: 131-140.

Takahashi , H. (1975). Process of functional sex reversal of the gonad in the female guppy, Poecilia reticulate treated with androgen before birth. Devel. Growth Differ., 17:167-175.

Takahashi, H. (1977). Effect of large dosage of methyltestosterone on the development of reproductive organs of juvenile guppy, Poecilia reticulate. Bull. Fac. Hokkaido Univ., 28 (1):6-19.

Tryfiates, G. P. (1986). Pyridocal phosphate and metabolism, In: D. Dolphin R. Poulson and O.Avramovil (Eds.), Vitamin B6; Pyridoxal phosphate. Part B,pp. 422-447. Jon Willy \&Sons, Inc. USA.

Washburn, B. S. ; Frye, D. J. ; Hung, S. O. ; Doroshov, S. I. and Conte, F. S.(1990). Dietary effects on tissue composition, oogenesis and the reproductive performance of female raibow trout Oncorhynchus mykiss. Aquacult., 90: 179-195.

Yamamoto, T. (1958). Artificial induction of functional sex-reversal in genotypic females of the medaka, Oryzias latipes. J.Exp. Zool., 137: 227-260.

Yamamoto, T. (1968). Permanency of hormone-induced reversal of sex-differentiation in medaka, Oryzias latipes. Annot. Zool. Jap., 41(4): 172-179. 
Yamamoto, T. (1969). Sex differentiation. Pages $117-175$ in W.S. Hoar and D. J. Randall (eds) Fish physiology. Vol. 3. Academic Press, New York.485 pp.

Yashouv, A. and Eckstein, B. (1965). Regulation and control of spawning. Bamidageh., 17:66-67. 
Table 1: Chentical composition of the control and active yeast diets.

\begin{tabular}{|c|c|c|c|c|c|c|}
\hline \multirow[t]{2}{*}{ Component (\%) } & \multirow{2}{*}{$\begin{array}{c}\text { Confrol } \\
\text { diet }\end{array}$} & \multicolumn{5}{|c|}{ Active yeast } \\
\hline & & $\mathrm{lg} / \mathrm{kg}$ & $2 \mathrm{~g} / \mathrm{kg}$ & $3 g / k g$ & $4 g / \mathrm{kg}$ & $5 g / k g$ \\
\hline Dry matrer & 92.37 & 92.41 & 92.51 & 92.74 & 92.85 & 92.93 \\
\hline Cinde prolsin & 34.86 & 35.25 & 35.53 & 35.78 & 35.94 & 36.33 \\
\hline Ether extract & 5.11 & $5 / 4$ & 5.16 & 5.19 & 5.21 & 5.21 \\
\hline Crande fiber & 4.75 & 4.76 & 4.81 & 4.84 & 4.86 & 4.89 \\
\hline$A s h$ & 8.83 & 8.88 & 8.93 & 8.98 & 9.03 & 9.08 \\
\hline Nitrogen fiec extract & 46.45 & +5.97 & +5.57 & +5.21 & 44.96 & 44.46 \\
\hline
\end{tabular}

Table 2: The average body weight, hepatosomatic and gonadosomatic indeces of Oreochromis nilotica fod differen levels of active yeast.

\begin{tabular}{|l|c|c|c|c|c|c|}
\hline $\begin{array}{l}\text { Treatment } \\
\text { Parameter }\end{array}$ & $\begin{array}{c}\text { Control } \\
\text { diet }\end{array}$ & \multicolumn{5}{|c|}{ Active yeast } \\
\cline { 3 - 7 } & & $1 \mathrm{~g} / \mathrm{kg}$ & $2 \mathrm{~g} / \mathrm{kg}$ & $3 \mathrm{~g} / \mathrm{kg}$ & $4 \mathrm{~g} / \mathrm{kg}$ & $5 \mathrm{~g} / \mathrm{kg}$ \\
\hline Whitial Body & 1.67 & 1.65 & 1.64 & 1.66 & 1.67 & 1.65 \\
Weight(g/Fish) & & $\mathrm{d}$ & $\mathrm{bc}$ & $\mathrm{a}$ & $\mathrm{b}$ & $\mathrm{bc}$ \\
Final body & 16.8 & 18.90 & 22.20 & 26.16 & 22.80 & 21.25 \\
weight (g/fish) & & & & & & \\
Hopatosomatic & 1 & 2.1 & 1.6 & 2.6 & 1.4 & 1.7 \\
index(HIS) & \pm 0.27 & \pm 0.23 & \pm 0.25 & \pm 0.21 & \pm 0.35 & \pm 0.41 \\
Male (GSl) & 0.7 & 1 & 2 & 0.8 & 1.5 & 1.7 \\
& \pm 0.04 & \pm 0.11 & \pm 0.05 & \pm 0.09 & \pm 0.14 & \pm 0.16 \\
Feniale (GSI). & 1.2 & 0.3 & 4.5 & 9.7 & 8.4 & notfound \\
& & & & & & \\
\hline
\end{tabular}




\section{EXPLANATION OF FIGURES}

Fig. 1: Photomicrograph of a testis, control group, showing the normal mature lobules and the sperm duct distended with spermatozoa (S). X 36

\section{ry}

Fig. 2: Photomicrograph of a control ovary showing ripe oocytes in normal 3 yolk stage. $X 90$

Fig. 3: Photomicrograph of a testis showing marked proliferation of the connective tissue (ct), many blood vessels packed with erythrocytes were visible between lobules (L) and extensive hemorrhagic necrosis. Atrophy of interstitial cells X 360

Fig. 4: Photomicrograph of a testis showing invasion of the blood vessel (bv) which were packed with erythrocytes (E). Many erythrocytes invaded the lobules (L) causing the atrophy of testis. X 360

Fig. 5: Photomicrograph of a testis showing enlargement of spermatogonia $(\mathrm{g})$ which liad abnormal appearance indicted by dense chromatin and degenerated cytoplasmn. Pyknosis of nuclei of spematocytes (P) and sperm's head (S). Disappearance of lobule wall. X 900

Fig. 6: Photomicrograph of a testis showing the degeneration of lobule wall (L), Pyknosis and necrosis (P) of all germ cells. $X$ 900

Fig. 7: Photomicrograph of a testis showing, the enlargement of spermatogonia (g), disintegration of spermatozoa (S) whose nuclei became pyknotic (P) and disappearance of nest membrane (M). X 900

Fig. 8: Photomicrograph of the ovary showing degenerated oocytes, hypertrophy of granulosa layer (gl). X 36

Fig. 9: Photomicrograph of the ovary showing the invasion of blood vessel and hypertrophy of granulose (arrow). X 360 
Fig. 10: Photomicrograph of the ovary showing edema and the interfollicular tissue contained leukocytes, and red blood cells and nuclear deformation (N). X 225.

Fig. 11: Photomicrograph of the ovary showing spent ovary with completely degenerated oocytes (DC). X 36

Fig. 12: Photomicrograph of a testis showing the appearance of oviform cell inside the testis (arrow). X 900

Fig. 13: Photomicrograph of the ovotestis showing the presence of oocytes at the outer region of the testis (arrow). X 36 

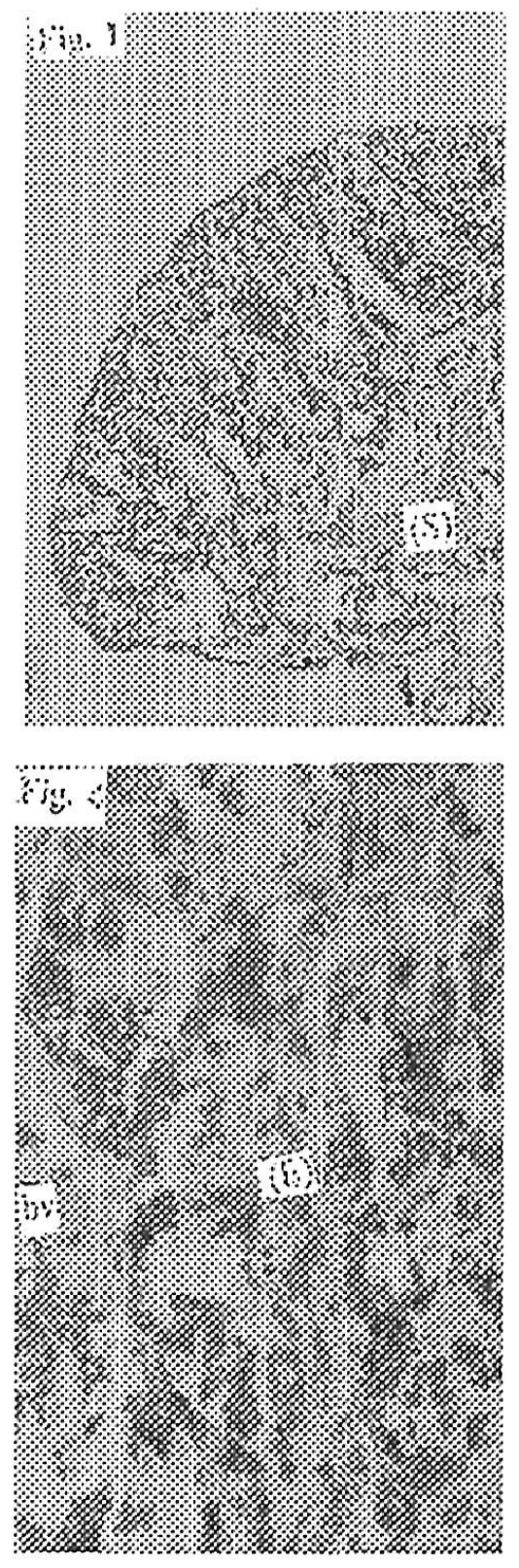
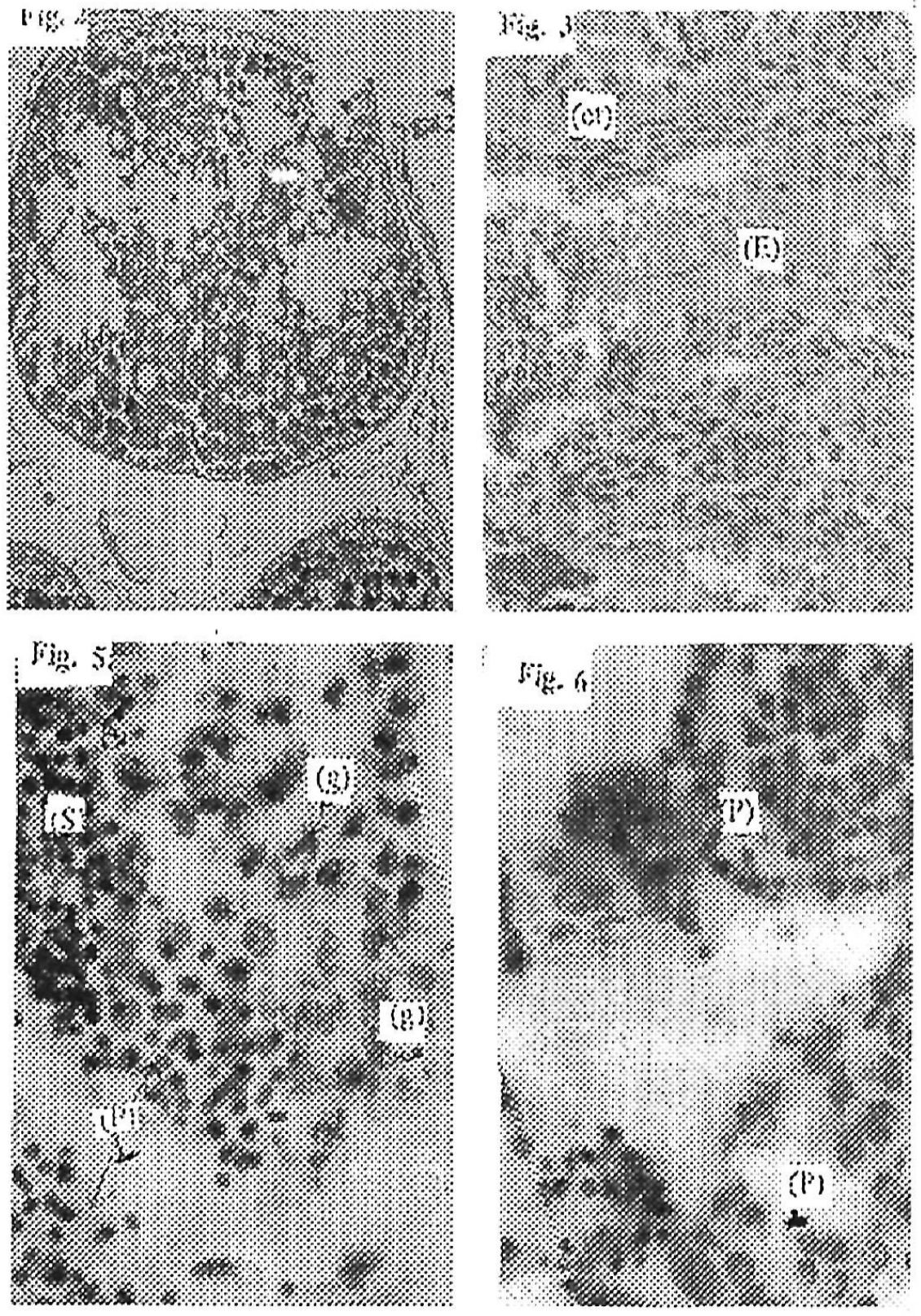

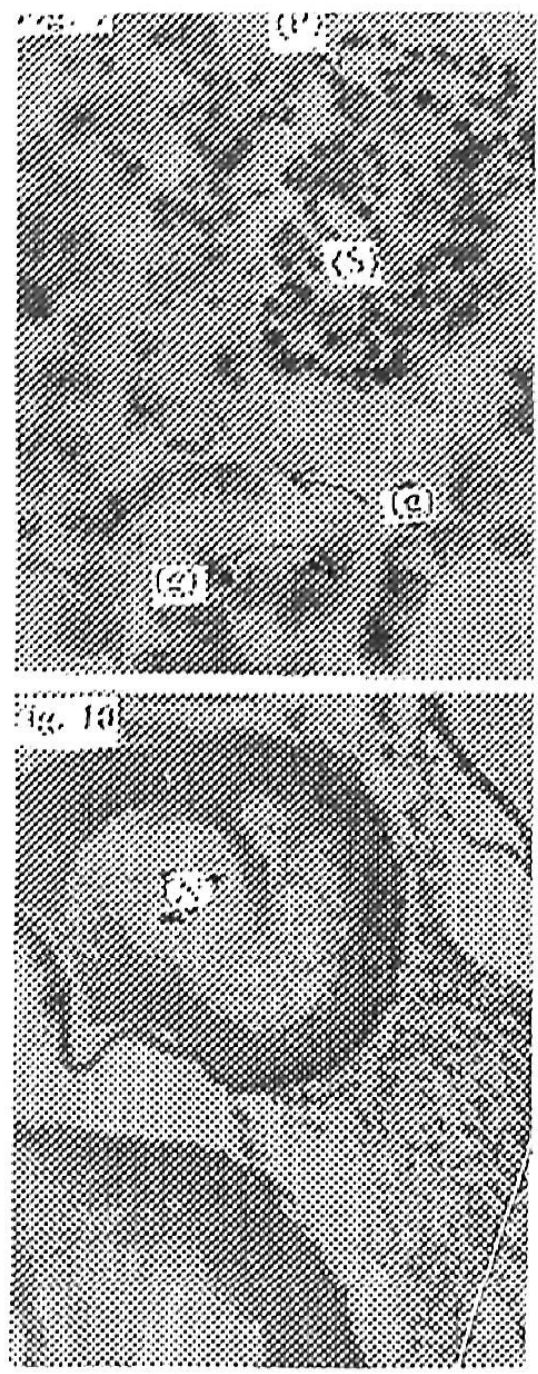
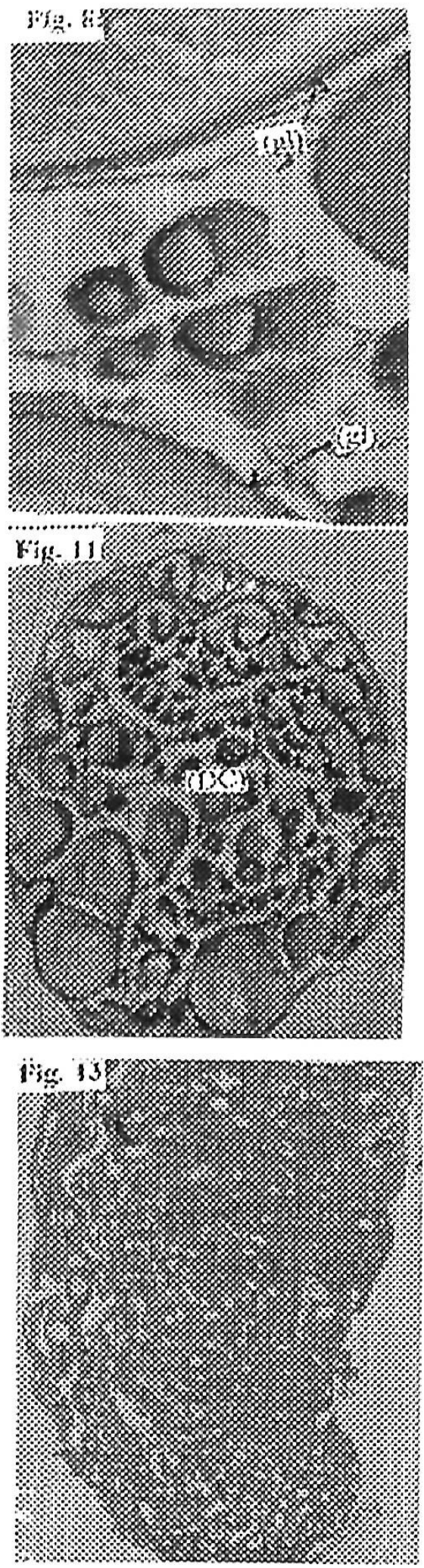
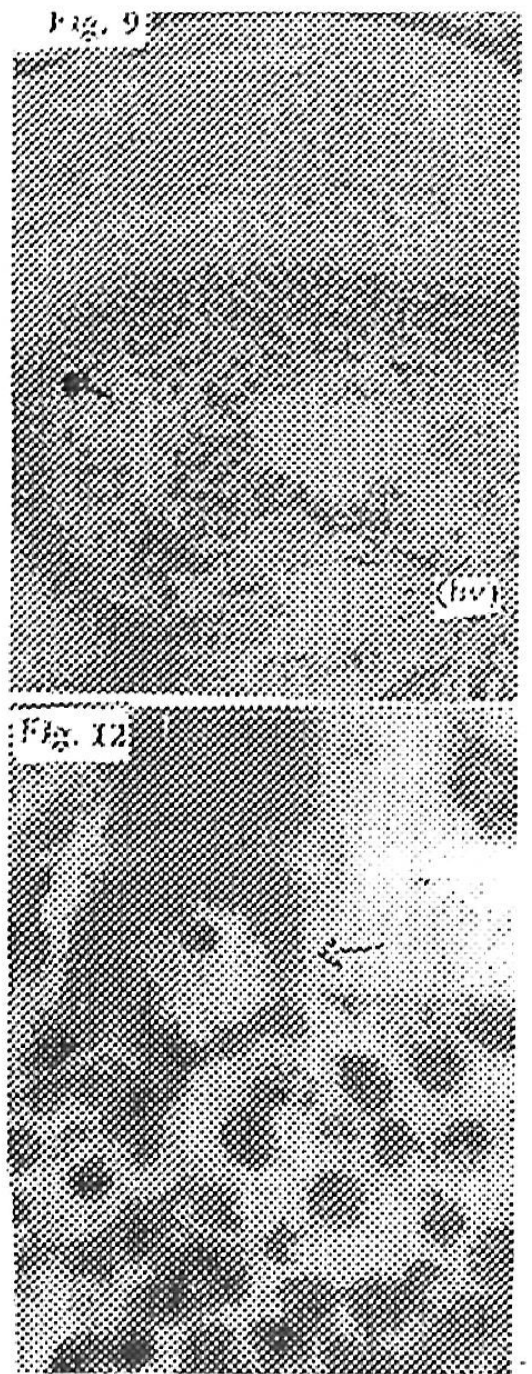